\title{
«Green» operation of a building - an object of cultural heritage
}

\author{
Olga Yanina ${ }^{1, *}$, Alexander Yanin ${ }^{1}$, Anton Chigarev $^{1}$, and Yanina Yanina ${ }^{1}$ \\ ${ }^{1}$ Voronezh State Technical University, 20 letiya Oktyabrya st., 84, Voronezh 394006, Russian Federation
}

\begin{abstract}
The aim of the study is to determine the further «green» operation of a building - an object of cultural heritage in technogenic conditions that formed in the 20-21 centuries, based on monitoring the actual engineering and geological conditions of the urban historical territory of Voronezh. The study of the engineering-geological conditions of the territory and the structures of the building was carried out in three stages. At the first stage, a reconnaissance survey was carried out to identify surface forms of manifestation of modern engineering and geological processes; at the second stage - examination and monitoring of soil properties of the foundations and the building structures; at the third stage - calculation of slope stability in the Midas GTS NX software package and selection of the optimal slope reinforcement with a retaining wall. Changes in the physical properties of soils and the violation of soil conditions on the slope of the historical territory of Voronezh during technogenic soaking of soils were revealed. Calculation of slope stability in the Midas GTS NX PC revealed the influence of the surrounding modern buildings on the deformation of the building structures object of cultural heritage. The influence of technogenic changes in slope stability in the process of modern development on the urban historical territory on the «green» ecology, i.e. safe operation of the building - a cultural heritage site.
\end{abstract}

\section{Introduction}

Preservation and adaptation of buildings - cultural heritage sites located in urban historical areas for new functions in modern man-made conditions is an important and, as a rule, technically difficult task [1-6]. It is necessary to timely monitor the existing actual engineering and geological conditions of urban historical areas for further "green» safe operation of buildings - cultural heritage sites [7-10].

\section{Materials and methods}

The analysis of changes in soil conditions and the development of slope processes in the urban historical territory is carried out on the example of the site of the building - an object of cultural heritage of regional significance "Babushkin's House" in Voronezh.

\footnotetext{
${ }^{*}$ Corresponding author: yaninaoi@yandex.ru
} 
The residential building "Babushkin's House" was built in 1907. The building is a twostorey residential building with dimensions in plan $15.8 \times 15.7 \mathrm{~m}$. All four facades of the building have the same decor with elements of neoclassicism. The rectangular brick volume is complemented by a projection that is strongly removed and off-center. Terraces located one above the other adjoin the risalit, the upper terrace rests on four columns. The floors of the house are separated by an interfloor cornice. The cornice of the building is complemented by a frieze with panels and overlays. The lintel of the rectangular windows on the first floor and arched windows on the second floor is made of keystone. The ground floor terrace is fenced with a metal grille with a modern design. The foundation and walls of the building are made of solid ceramic bricks. The slabs are a boardwalk on wooden beams, the roof frame includes a rafter structure with a crate, on top of which a covering of asbestos-cement sheets is made. The layout of the building has now undergone significant changes related to the adaptation of the building to modern functions.

General views of the building facades are shown in fig. 1 and 2.

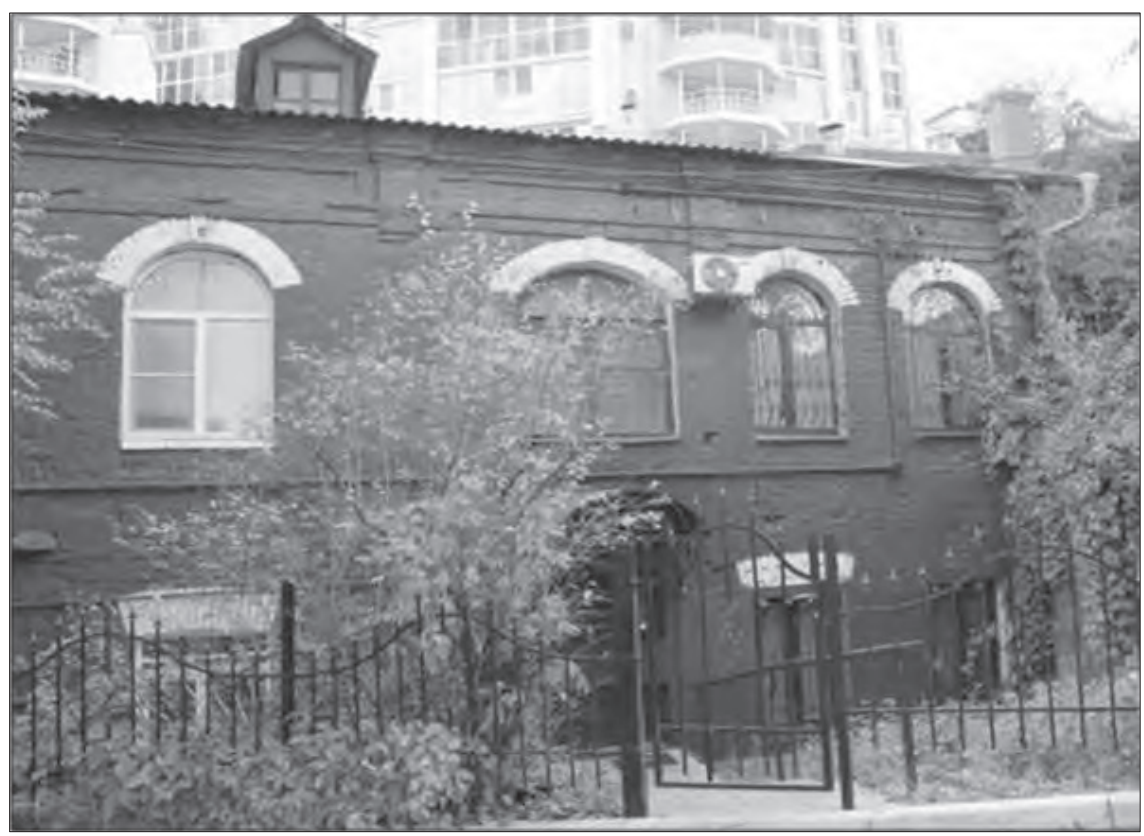

Fig. 1. General view of the main facade of the building.

A reconnaissance survey was carried out to identify surface forms of manifestation of modern engineering and geological processes that negatively affect the stability of the slope at the site of the building of a residential building, and consisted in examining the site of exploration.

To inspect the condition and properties of the soils of the foundations, the pits were opened outside near the bearing walls of the building. 3 pits with a depth of $1.90 \ldots 2.05 \mathrm{~m}$ were opened. For laboratory studies, samples of undisturbed structure were taken from the pits to determine the physical and mechanical properties of soils. 


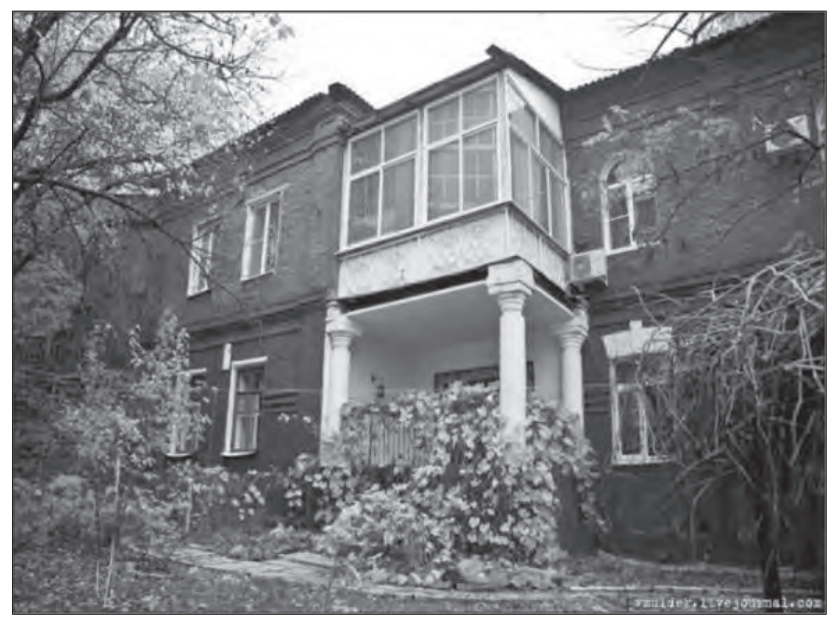

Fig. 2. General view of the building facade from the courtyard side.

The survey of the building structures was carried out in three stages. Preparatory work: familiarization with the object, study of the project documentation for the object. Visual inspection: identification of the main defects and damage to structures by external signs. During visual examination, defects and damages were recorded in the form of descriptions, sketches. Detailed instrumental examination: execution and registration of measurement work, clarification and detailing of defects and damages identified in the process of visual inspection, establishment of actual loads and impacts on the building, verification calculations of the bearing capacity of foundation soils.

The calculation of the stability of the slope at the site of the building was carried out by the finite element method in the software package Midas GTS NX [11-15].

\section{Results}

\subsection{Results of the study of soil conditions}

The geological structure of the site is attended by alluvial medium-Quaternary clay deposits, overlain by modern man-made fill soils.

The lithologic-stratigraphic section of the site is as follows (fig. 3 and 4):

- layer 1. IGE1, tQIV - bulk soil, represented by a mechanical mixture of soil, loam with rare inclusions of construction waste and with the remains of the root system of trees. The deposits were opened in pit No. 2 under the bottom of the foundations. Bulk soil is the basement soil. The thickness of the layer is $0.75 \mathrm{~m}$. The ground is packed. Also, the deposits were opened in pits No. 1 and No. 2 on the walls opposite to the foundations. The layer thickness is $0.80 \ldots 1.35 \mathrm{~m}$.

- layer 2. IGE-2, aQII - light brown semi-hard loam. Sediments were uncovered under the bottom of the foundations in pit No. 1, the exposed layer thickness is $0.60 \ldots 0.80 \mathrm{~m}$. On the opposite walls of the pits No. 1 and No. 2, the layer thickness is $0.70 \ldots 0.80 \mathrm{~m}$. 


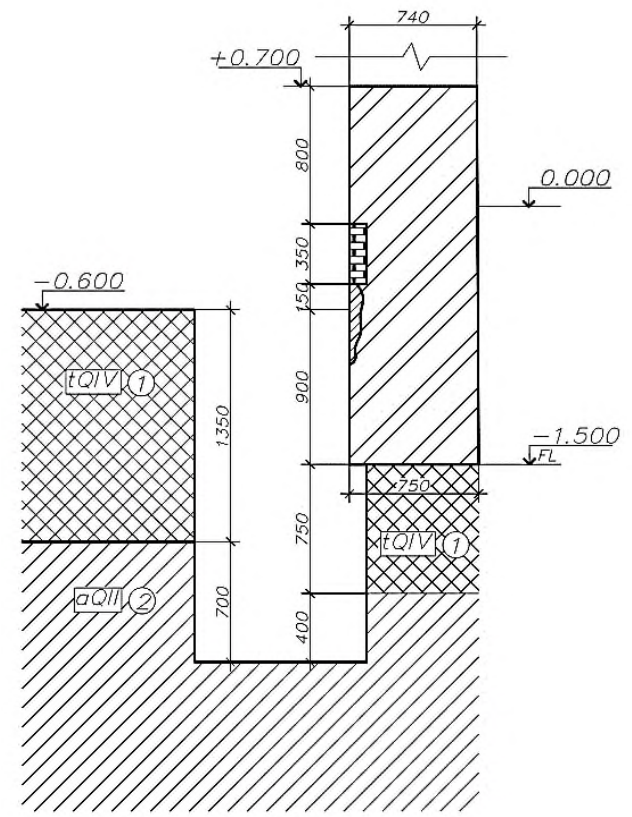

Fig. 3. Vertical schematic section of the pit №1.

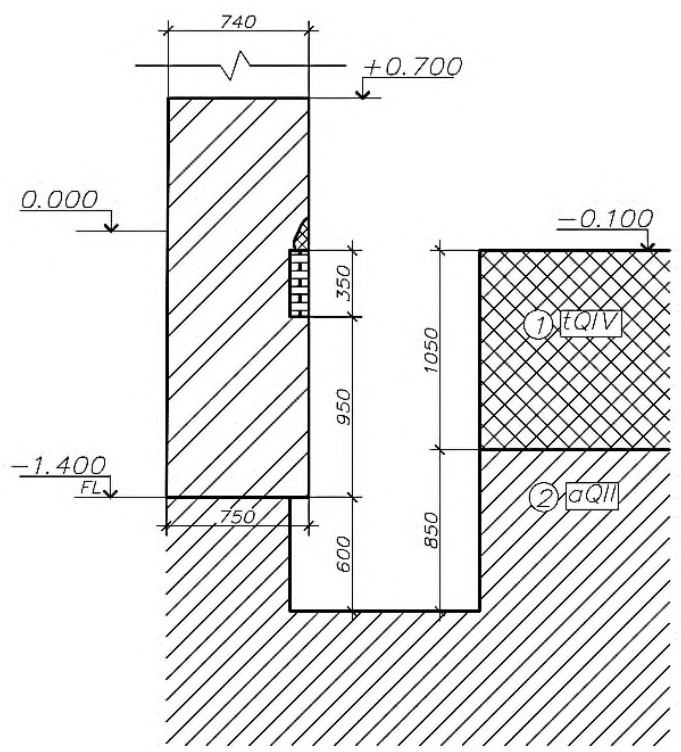

Fig. 4. Vertical schematic section of the pit №2.

The soil conditions of the site were investigated in 2015. and 2019. Changes in the values of indicators of physical properties of soils of the foundation of the building for the period $2015 \ldots 2019$ are shown in fig. 5. Analysis of the data obtained showed an increase in soil moisture by $19.8 \%$ and, as a consequence, a change in the flow rate IL. These changes in the physical properties of soils indicate the technogenic soaking of the soils of the base of the building and the violation of the soil conditions of the slope of the territory [11]. 


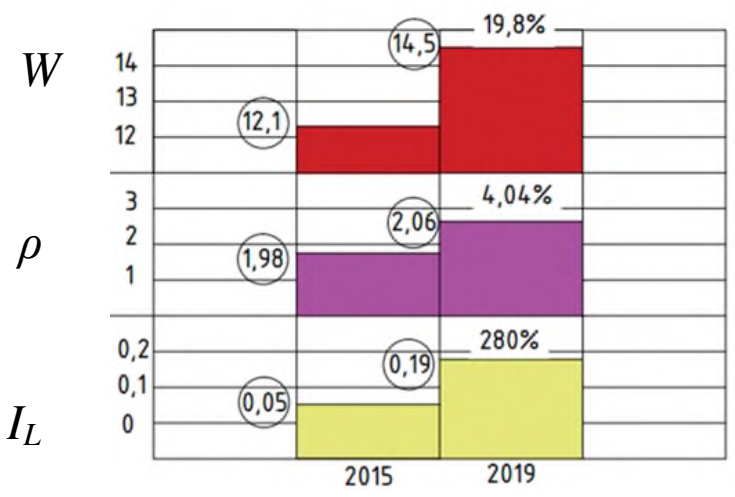

Fig. 5. Diagram of changes in moisture $W$, density $\rho$ and flow rate IL loam IGE-2 for the period 20152019.

\subsection{Research results of technogenic conditions}

The technogenic conditions of the site of the location of the building under study are determined by the conditions of dense urban development, which has developed in the central part of the slope of the right shore of the historical territory of Voronezh (fig. 6). Modern technogenic conditions of the site change during the entire period of operation of the building - a cultural heritage site. It is surrounded by residential buildings built in the 20th and $21 \mathrm{st}$ centuries: a five-storey building (60-65, 20th century) and from the courtyard side - a twelvestorey building (early 21 st century). Structures and soils of the foundation of the building - a cultural heritage object experienced significant man-made loads that arose during the construction of residential buildings in the immediate vicinity and disturbed the stability of the slope of the site $[12,13]$.

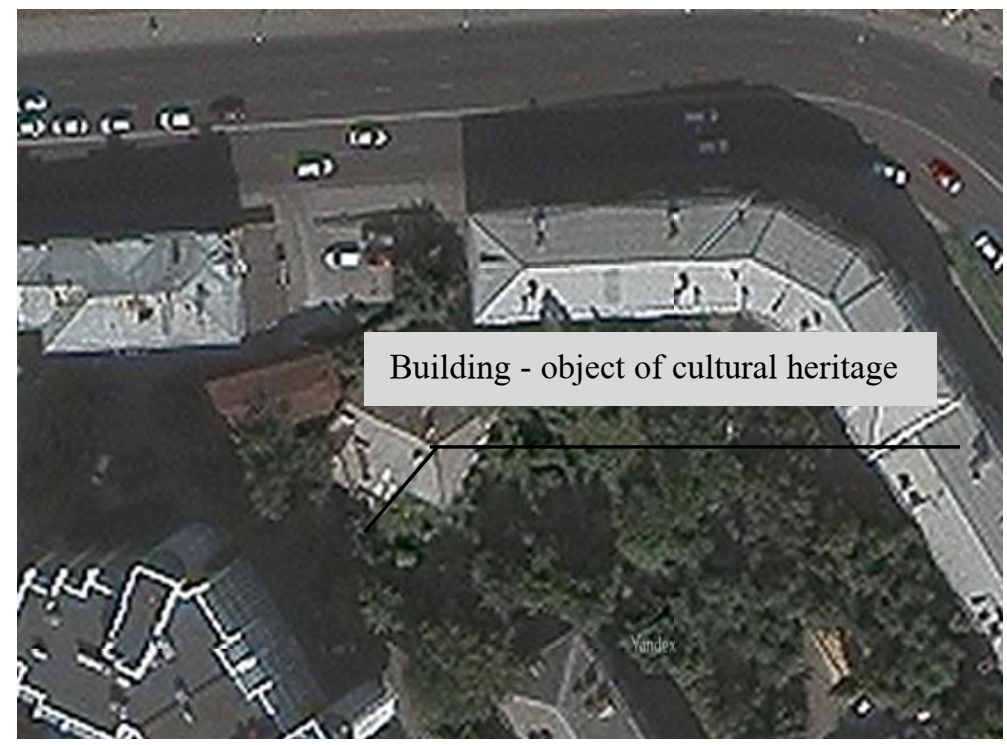

Fig. 6. Technogenic conditions of the study site. 


\subsection{Inspection results of building constructions}

The foundations of the walls of the building are tape, made of solid masonry of solid ceramic bricks on a complex mortar (fig. 3 and 4). The laying of the foundations of the walls is homogeneous from the same type of ceramic bricks. The width of the base of the foundations of the outer longitudinal and transverse load-bearing walls is $0.75-0.90 \mathrm{~m}$. The depth of the base of the foundations is $0.90-1.30 \mathrm{~m}$ from the surface level of the adjacent territory.

Defects and damage to the masonry foundations: moisture below the level of the soil surface, decrease in the strength of the solution of the outer layer of the masonry to grade M10.

The soil base of the foundations of the walls of the building is heterogeneous, incl. and specific soils: bulk soil (IGE-1) and semi-solid non-subsiding loams (IGE-2).

The conditions for limiting the pressure on the foundation soils are met and the bearing capacity of the soils is sufficient for the actual dimensions of the foundations for the outer load-bearing walls, with the exception of the foundation section of the outer wall of the inner facade of the building.

Inspection results of wall structures. The masonry of the walls is made of solid ceramic bricks on a complex mortar. The thickness of the outer walls is $0.74-0.90 \mathrm{~m}$. The walls are made mainly by masonry.

Defects and damage to the masonry of the outer walls: cracks in the masonry of the bearing walls with an opening width of $1.0 \mathrm{~mm}$ to $8.0 \mathrm{~mm}$, incl. through cracks in the cornice part; destruction and moistening of the outer layer of masonry along the perimeter of the building in the basement part. The cartogram of cracks and damage to the outer walls of the building is shown in fig. 7.

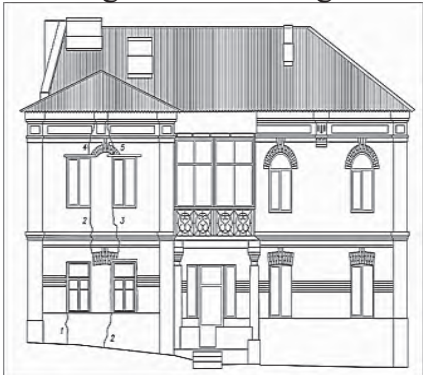

a

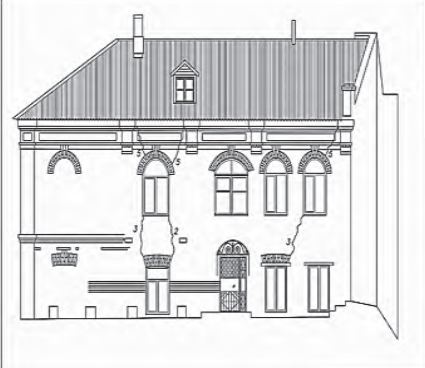

b

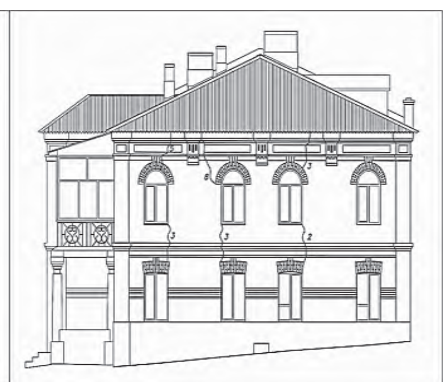

c

Fig. 7. Cartograms of cracks in the walls of the building: where, $a$ - on the main facade; $b$ - on the side facade; $\mathrm{c}$ - on the facade from the side of the courtyard.

The technical condition of the soils of the base and structures of the building as a whole should be classified as «limited working condition».

Slope stability was calculated using the finite element method in the Midas GTS NX software package. According to the results of the calculation, taking into account the influence of the stability of the slope on the studied building after the construction of the surrounding modern buildings, the greatest deformations in the building-object of cultural heritage occurred after the construction of a five-storey residential building in the years 60-65 of the 20th century, located below the slope. The displacements of the walls along the Y axis (draft) are uneven and at the selected points were $-4.66 \mathrm{~cm}$ and $-3.72 \mathrm{~cm}$, which indicates the roll of the building under study. The relative displacements were $(0.047 \mathrm{~m}-0.037 \mathrm{~m}) / 12.29 \mathrm{~m}=$ $0.0008>0.0007$, which is an excess of the maximum permissible values (fig. 8). 


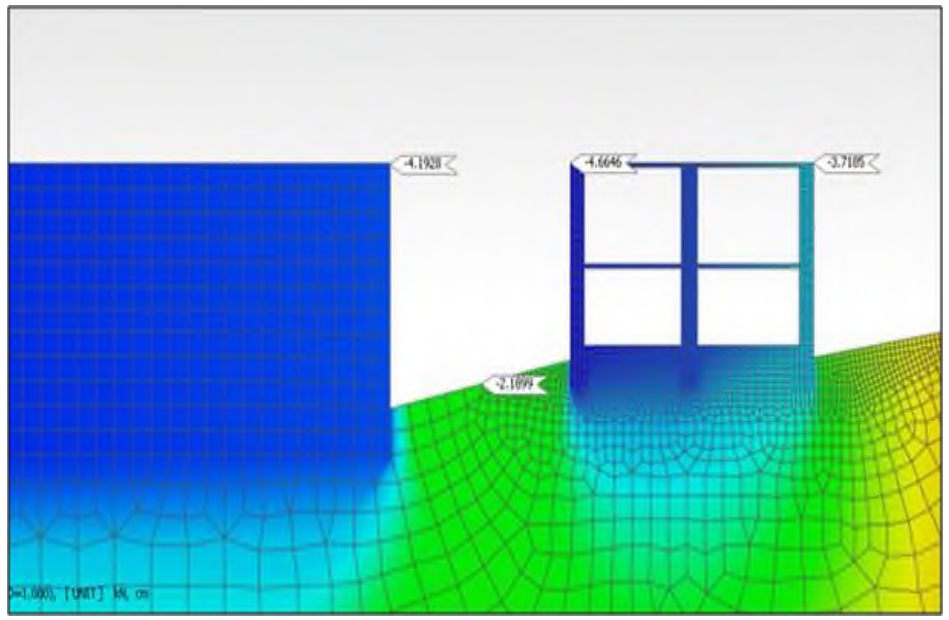

Fig. 8. Movements of the walls of the building (51a) along the $\mathrm{Y}$ axis.

To prevent further deformations of the building under study, an option was considered to enhance the bearing capacity of the slope soils by erecting a retaining wall $35.0 \mathrm{~m}$ long from rammed piles with a diameter of $d=0.4 \mathrm{~m}$ between buildings $51 \mathrm{a}$ and $47 \mathrm{a}$. The layout of the designed retaining wall made of rammed piles is shown in fig. 9.

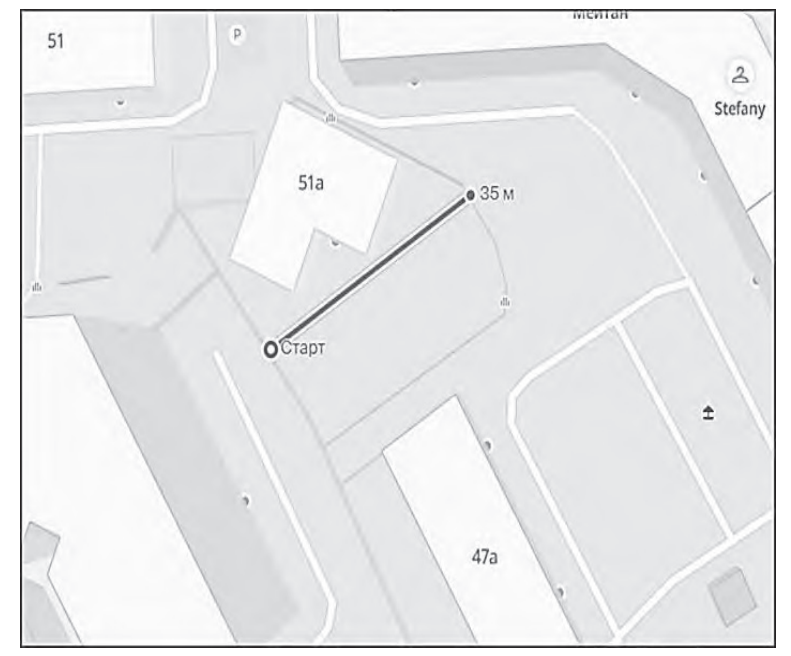

Fig. 9. The layout of the projected retaining wall made of reinforced concrete piles.

The choice of the most optimal option for reinforcing the slope with a retaining wall from a number of reinforced concrete rammed piles between buildings 51a and 47a was made based on a comparison of the results of calculation options in the Midas GTS NX PC:

Option 1: piles $1=5.0 \mathrm{~m}, \mathrm{~d}=0.4 \mathrm{~m}$, distance from the building $(51 \mathrm{a})-1.0 \mathrm{~m}$.

Option 2: piles $1=5.0 \mathrm{~m}, \mathrm{~d}=0.4 \mathrm{~m}$, distance from the building $(51 \mathrm{a})-2.0 \mathrm{~m}$.

Option 3: piles $1=4.0 \mathrm{~m}, \mathrm{~d}=0.4 \mathrm{~cm}$, distance from the building (51a) $-2.0 \mathrm{~m}$.

Option 4: piles $1=3.0 \mathrm{~m}, \mathrm{~d}=0.4 \mathrm{~cm}$, distance from the building $(51 \mathrm{a})-2.0 \mathrm{~m}$.

Option 5: piles $1=5.0 \mathrm{~m}, \mathrm{~d}=0.4 \mathrm{~cm}$, distance from the building (51a) $-3.0 \mathrm{~m}$.

To strengthen the slope with a retaining wall, according to the calculation results, option No. 5 was chosen: pile length $1=3.0 \mathrm{~m}$, diameter $\mathrm{d}=0.4 \mathrm{~m}$, wall distance from the building (51a) $-2.0 \mathrm{~m}$, as the most optimal. With these parameters, the piles and the distance from the 
building, according to the results of calculating the deformations along the $\mathrm{Y}$ axis, significantly decreased and amounted to $-0.12 \mathrm{~cm}$ and $0.29 \mathrm{~cm}$, which does not exceed the maximum permissible values of relative deformations $(0.12+0.29) / 12,29=0.0003<0.0007$ (fig. 10-12).

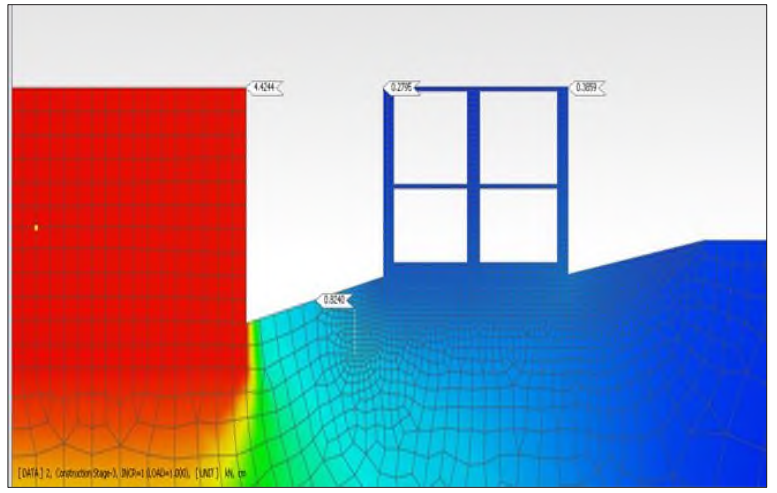

Fig. 10. Total displacements (deformations) of the scheme.

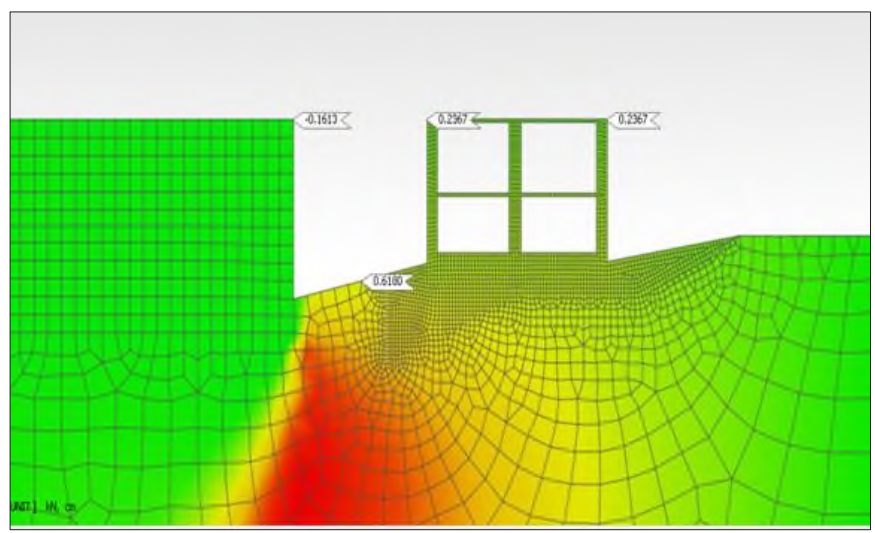

Fig. 11. Displacements along the axis of $X(\mathrm{~cm})$.

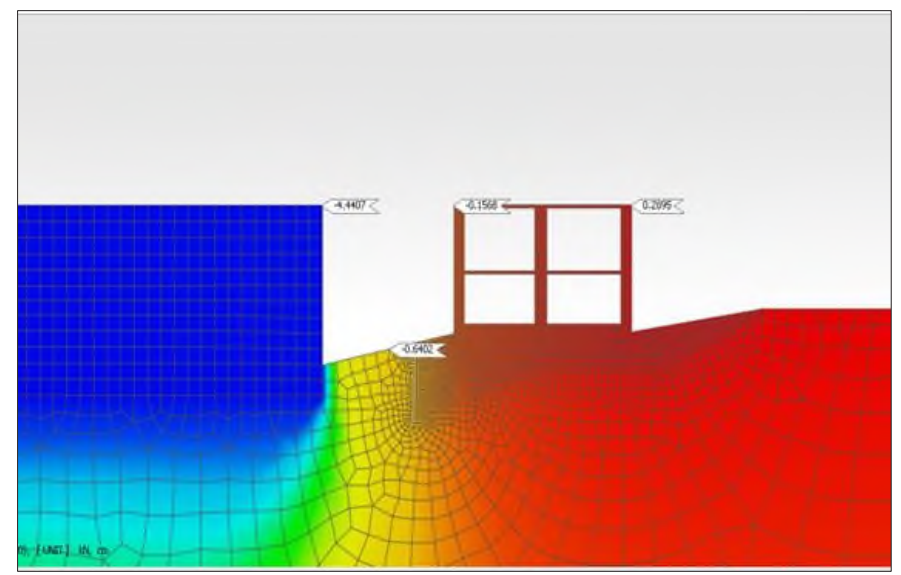

Fig. 12. Displacements along the axis of $Y(\mathrm{~cm})$. 


\section{Discussion}

The influence of the stability of the slope of the urban historical territory on the operation of the building - the object of cultural heritage is determined by the modern dynamic technogenic conditions of the surrounding buildings of the city center. As a result, the state of the soils and structures of the building is subject to change during both a long-term period of time associated with infill development and disruption of the slope stability, and a short-term period of time during man-made impacts on the foundation soils. The use of constructive measures based on numerical calculation methods in the Midas GTS NX PC allows you to choose the optimal option for strengthening the slope.

\section{Conclusions}

The study results analysis of soil conditions of the site of the building location - an object of cultural heritage of regional significance allows us to draw the following conclusions:

- the influence of changes in the stability of the slope of the urban historical territory on the safety of buildings operation - objects of cultural heritage, leading to the dynamic development of damage to building constructions;

- the results of the study can be used in the development of constructive measures for strengthening the soils of the slope to prevent the development of engineering and geological processes in urban historical areas.

\section{References}

1. P.A. Zhuravlev, A.M. Marukyan, Engineering protection of buildings, structures and territories as a factor of innovative development of spatial planning, Monthly Journal on Construction and Architecture 15(10), 1440-1449 (2020) DOI: 10.22227/19970935.2020.10.1440-1449

2. S.V. Solsky, S.A. Bykovskaya, Optimizing the landslide-prone slope stabilization, Monthly Journal on Construction and Architecture 14(10), 1258-1271 (2019) DOI: 10.22227/1997-0935.2019.10.1258-1271

3. V.V. Simonyan, A.G. Tamrazyan, On estimatingsafety of buildings and structures on landslide risk territories with account for landslide displacement force,moment of its displacement and acceleration, Proceedings of Moscow State University of Civil Engineering 7, 101-113 (2016) DOI: 10.22227/1997-0935.2016.7.101-113

4. V.A. Ilyichev, V.I. Kolchunov, N.V. Bakaeva, Principles of area development strategic planning (the case of the free state of Bavaria), Proceedings of Moscow State University of Civil Engineering 14, 2, 158-168 (2019) DOI: 10.22227/1997-0935.2019.2.158-168

5. V.A. Brylev, Yu.A. Korhova, Ancient and recent landslides in the Lover Volga region and factors of their formation, Geomorphology RAS 4, 37-47 (2010) DOI: 10.15356/0435-4281-2010-4-37-46

6. N.V. Karpova, Sustainable development of urban settlements: theoretical postulates and their practical implementation, Economy and ecology of territorial formations 3(3), 64-70 (2019) DOI: 10.23947/2413-1474-2019-3-3-64-70

7. D.A. Vallero, C. Brasier, Sustainable Design: The Science of Sustainability and Green Engineering (John Wiley \& Sons, Inc, 2008) DOI: 10.1002/9780470259603 
8. V.V. Konyushkov, Engineering protection of territories from slope shift processes taking into account natural conditions and technogenic loads, Bulletin of Civil Engineeers 2, 137-142 (2017) DOI: 10/23968/1999-5571-2017-14-2-137-142

9. V.I. Telichenko, Green technologies of living environment: concepts, terms, standards, Proceedings of Moscow State University of Civil Engineering 12, 4(103), 364-372 (2017) DOI: 10.22227/1997-0935.2017.4.364-372

10. V.I. Telichenko, V.M. Roitman, A cause-and-consequence analysis of serious emergencies with the aim of providing integrated safety of buildings and installations, Monthly Journal on Construction and Architecture 15(1), $72-84$ (2020) DOI: 10.22227/1997-0935.2020.1.72-84

11. A. Belostotsky, P. Akimov, V. Sidorov, T. Kaytukov, About development of adaptive mathematical models, numerical and semianalytical methods as theoretical foundation of structural health monitoring systems. Fundamental, exploratory and applied research of the RAASN on scientific support for the development of architecture, urban planning and the construction industry of the Russian Federation in 2017: collection of articles. RAASN, 2. Moscow, ASV Publ., 71-78 (2018) DOI: 10.22337/9785432302663-71-78

12. A.V. Patrikeev, E.K. Salatov, Fundamentals of the methods of dynamic monitoring of deformation characteristics of buildings and structures, Monthly Journal on Construction and Architecture 8(1), 133-138 (2013) DOI: 10.22227/1997-0935.2013.1.133-138

13. A.V. Patrikeev, Dynamic monitoring of engineering structure as a key element of its technical security, Monthly Journal on Construction and Architecture 3, 133-140 (2014) DOI: 10.22227/1997-0935.2014.3.133-140

14. V.V. Antipov, V.G. Ofrikhter, Modern nondestructive method of researching of geological-engineering section, PNRPU Construction and Architecture Bulletin 7(2), 3749 (2016) DOI: 10.15593/2224-9826/2016.2.04

15. Yu.A. Kalugina, D. Kek, Ya.A. Pronozin, Determination of soil deformation moduli after National Building Codes of Russia and Germany, Magazine of Civil Engineering 7(75), 139-149 (2017) DOI: 10.18720/MCE.75.14 